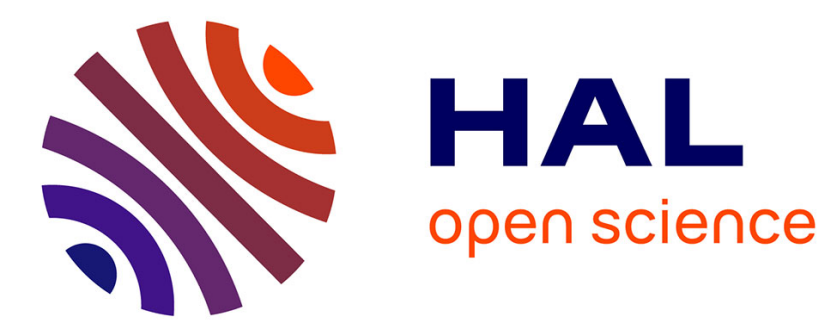

\title{
SURFACE INDUCED FERROMAGNETISM IN 3He
}

\author{
A. Ahnonen, T. Alvesalo, T. Haavasoja, M. Veuro
}

\section{To cite this version:}

A. Ahnonen, T. Alvesalo, T. Haavasoja, M. Veuro. SURFACE INDUCED FERROMAGNETISM IN 3He. Journal de Physique Colloques, 1978, 39 (C6), pp.C6-285-C6-286. 10.1051/jphyscol:19786127 . jpa-00217532

\section{HAL Id: jpa-00217532 https://hal.science/jpa-00217532}

Submitted on 1 Jan 1978

HAL is a multi-disciplinary open access archive for the deposit and dissemination of scientific research documents, whether they are published or not. The documents may come from teaching and research institutions in France or abroad, or from public or private research centers.
L'archive ouverte pluridisciplinaire HAL, est destinée au dépôt et à la diffusion de documents scientifiques de niveau recherche, publiés ou non, émanant des établissements d'enseignement et de recherche français ou étrangers, des laboratoires publics ou privés. 
SURFACE INDUCED FERROMAGNETISM IN ${ }^{3} \mathrm{He}$

\author{
A.I. Ahnonen ${ }^{\star}$, T.A. Alvesalo, T. Haavasoja, and M.C. Veuro \\ Low Temperature Laboratory, Helsinki University of Technology, SF-02150 Espoo 15, Finland
}

\begin{abstract}
Résumê.- La susceptibilitê et les temps de relaxation transverses et longitudinaux des noyaux d' ${ }^{3}$ He dans une poudre de charbon $(\phi 9 \mathrm{~nm})$ ont étê mesurés jusqu'à $0.4 \mathrm{mK}$ par RMN pulsée. Les résultats indiquent que $1^{\prime 3} \mathrm{He}$ près de $\mathrm{I}^{\prime}$ interface solide-liquide a une tendance ferromagnétique aux plus basses temperatures.
\end{abstract}

Abstract.- Pulsed NMR measurements of the susceptibility and of the transverse and longitudinal relaxation times of ${ }^{3} \mathrm{He}$ intermixed with $9 \mathrm{~nm}$ carbon particles down to $0.4 \mathrm{mK}$ show that the solidliquid system near the surfaces favours ferromagnetic order below $10 \mathrm{mK}$ and approaches a ferronagnetic transition at the lowest temperatures.

Recent measurements on ${ }^{3} \mathrm{He}$ at millidegree temperatures inside a stack of mylar plates $4 \mu \mathrm{m}$ apart /1/ and intermixed with ultrafine carbon particles $/ 2 /$ showed a pronounced enhancement of the susceptibility as compared with that of normal bulk Fermi-liquid. The excess susceptibility exhibited a ferromagnetic Curie-Weiss behaviour $x=1 /(T-\theta)$ with $\theta$ roug1y $0.7 \mathrm{mK}$. We report here pulsed NMR measurements on ${ }^{3} \mathrm{He}$ intermixed with $9 \mathrm{~nm}$ carbon particles at $0,6,15$ and 25 bar bulk pressure well below that temperature as well as above the onset of the ferromagnetic trend of the susceptibility. The apparent transverse relaxation time $\tau_{2}^{\star}$ was also determined at the various pressures; the longitudinal relaxation time $\tau_{1}$ was measured on $1 \mathrm{y}$ at 0 bar. All measurements were performed in a magnetic field of $28 \mathrm{mT}$.

Our sample consisted of a cylindrical NMR coil, $5 \mathrm{~mm}$ in diameter and $6 \mathrm{~mm}$ long, filled to $6 \%$ with carbon black /3/. The characteristic surface area of the carbon powder was measured with the BET-method to be $350 \mathrm{~m}^{2} / \mathrm{g}$ yielding for the total surface area fo our sample $4.9 \mathrm{~m}^{2}$. The temperatures were determined by measuring the susceptibility of powdered platinum confined in a similar coil and in contact with the ${ }^{3} \mathrm{He}$ sample; the Korringa relation was employed for calibration of the thermometer.

The amplitude of the free induction signal, extrapolated to time $t=0$, is proportional to the susceptibility of the sample. The measured signals appeared to be composed of two contributions, one decaying much slower $\left(\tau_{2}^{*} \simeq 400 \mu\right.$ s) than the other

* Present address : Department of Physics, Cornel1 University, Ithaca, New York 14853, USA $\left(\tau_{2}^{\star} \simeq 40 \mu \mathrm{s}\right)$. We call the extrapolated quantities $X_{1}$ and $X_{2}$, respectively.

Our data on $X_{2}$ show no pressure dependence within the scatter and susceptibility follows a curie Weiss 1 aw $\theta=-0.09 \mathrm{mK}$. This is in accordance with an antiferromagnetic interaction with $\mathrm{J} / \mathrm{k}_{\mathrm{B}}=\frac{4}{2} \theta=$ $-0.06 \mathrm{mK}$ if we use $z=6$ as the number of nearest neighbours. Bulk solid ${ }^{3} \mathrm{He}$ ordinarily exhibits an antiferromagnetic exchange interaction ; the measured $\mathrm{J}$ would correspond to a molar volume of $21 \mathrm{~cm}^{3} /$ mole for solid ${ }^{3} \mathrm{He}$. The antiferromagnetic nature of the signal, its insensitivity to the applied pressure, and its short and constant $\tau_{2}^{*}$ suggest that $x_{2}$ is associated with a well-1ocalized sheet of ${ }^{3} \mathrm{He}$ atoms on the surfaces. We estimate the thickness of the layer to be $\simeq 1.2$ atomic layers.

Figure 1 shows the inverse of the major contribution, $X_{1}$, as a function of temperature at $p=0$. Assuming that $X_{2}$ originates from the next few surface layers, with a density $>\rho_{\text {bulk }}$ and a CurieWeiss type susceptibility, and from the Fermi-1iquid in the centre of the voids, we may write :

$$
x_{1}=\frac{c_{1}}{T-\theta}+c_{2} \text {, }
$$

where $c_{1}$ and $c_{2}$ are constants. The bulk liquid contribution can be separated by plotting $X_{1}$ vs. $T^{-1}$ $\rightarrow 0$. The $c_{2}$ 's at different pressures scale within $\pm 20 \%$ as the susceptibilities of bulk liquid ${ }^{3} \mathrm{He}$. In terms of the above model $\left(x_{1}-c_{2}\right)$ is ferromagnetic and weakly pressure dependent; the $\theta^{\prime} s$ range from 0.35 to $0.50 \mathrm{mK}$. The ratios of $\left(x_{1}-c_{2}\right)$ 's and $c_{2}$ 's yield for the thickness of the intermediate solid liquid region $4.5-5.5$ atomic layers. The deviation of the temperature dependence of 
$\left(x_{1}-c_{2}\right)$ from the Curie-Weiss law already at approximately $2 \theta_{1}$ may reflect the two-dimensional nature of the system.

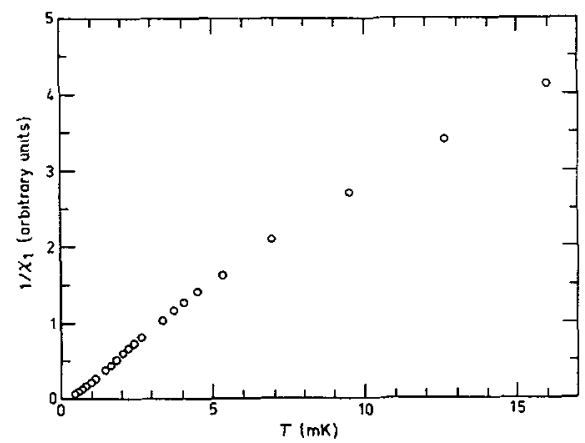
Fig. 1 : The inverse susceptibility $x_{1}^{-1}$ as a func-
tion of temperature at $p=0$.

The resemblance of the data in figure 1 to the solid ${ }^{3}$ He susceptibility data of Prewitt and Goodkind /4/ suggests another way of interpreting our data. If we assume that at temperatures between 10 and $20 \mathrm{mK}$ the antiferromagnetic susceptibility dominates and fit those data of the first term in eq. (1), we obtain $\theta=-2.6 \ldots-2.8 \mathrm{mK}$ at the different pressures. In this case, within the scatter of our data, the "excess" susceptibility appears to be proportional to $\mathrm{T}^{-2}$.

Our data on the apparent transverse relaxation time $\tau_{2}^{*}$ are shown in figure 2. $\tau_{2}^{*}$ is seen to be $1 i-$ near, slowly declining function of temperature down to $\sim 10 \mathrm{mK}$. At about $5 \mathrm{mK}$ it becomes constant and then grows rapidly towards the lowest temperatures. This is characteristic of a ferromagnet close to the transition $/ 5 /$.

of the suggestions for explaining the observed ferromagnetic behaviour in the solid-1iquid system of ${ }^{3} \mathrm{He} / 6 /, 17 /, / 8 /$, we consider the theory of vacancy induced ferromagnetism as the most appealing one. The onset temperature of the ferromagnetic trend in the susceptibility of both low-density solid and solid-liquid ${ }^{3} \mathrm{He}$ (we note in passing that it coincides with the inflection point of the melting curve) and of the anomalous Kapitza resistance $\mathrm{R}_{\mathrm{K}} \propto \mathrm{T}^{-1}$ below $\sim 10 \mathrm{mK}$ seems to indicate that these two phenomena are related and their common origin may be established within the framework of the vacancy theory.

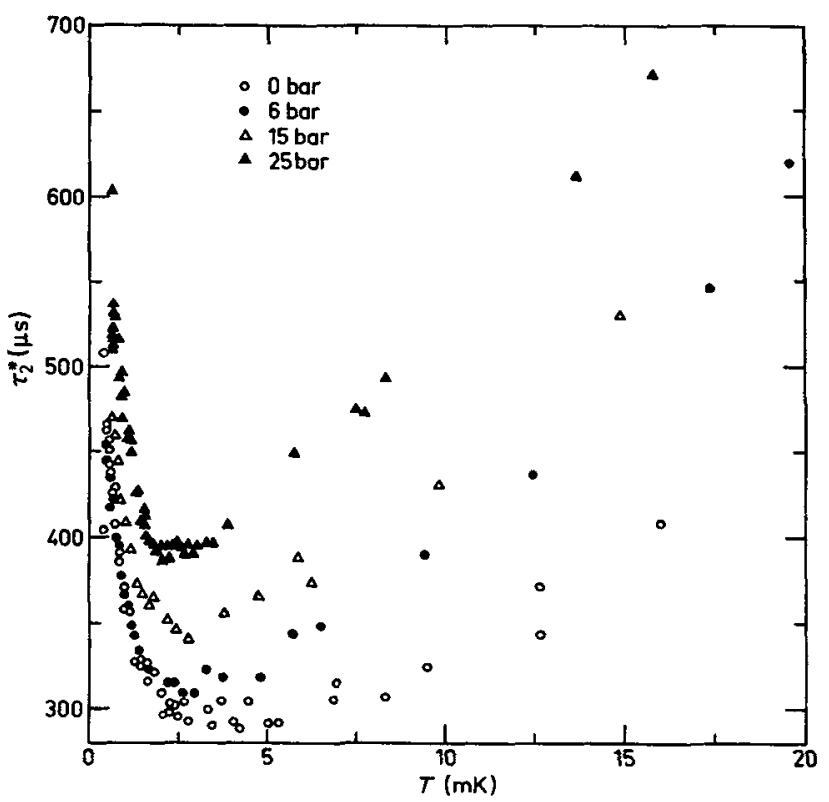

Fig. 2 : The apparent transverse relaxation time $\tau$ as a function of tcmperature at $0,6,15$, and 25 bar.

\section{References}

/1/ Ahonen, A.I., Kodama, T., Krusius, M., Paalanen, Richardson, R.C., Schoepe, W., and Takano, Y., J. Phys. C $\underline{9}$ (1976) 1665.

12/ Ahonen, A.I., Kokko, J., Lounasmaa, 0.V., Paalanen, M.A., Richardson, R.C., Schoepe, W., and Takano, $Y$., in "Quantum Fluids and Solids", eds. S.B. Trickey, E.D. Adams, and J.W. Dufty, (Plenum Press, New York) 1977, p. 171.

/3/ Ahonen, A.I., Gu1ly, W.J., Lounasmaa, O.V., and Veuro, M.C., paper $\mathrm{XXX}$ in these proceedings.

14/ Prewitt, T.C. and Goodkind, J.M., Phys. Rev. Lett. 39 (1977) 1283.

$\hat{j 5 /}$ see e.g. White, R.M., Quantum Theory of Magnetism, (McGraw-Hill, New York) 1970.

/6/ Beal-Monod, M.T. and Doniach, S., J. Low Temp. Phys. 28 (1977) 175.

/7/ Guyer, R.A., in "Physics at U1tralow Temperatures", ed. T. Sugawara, (Physical Society of Japan, Tokyo) 1978, p. 178.

$18 /$ Andreev, A.F., Marchenko, V.I., and Meyerovich, A.E., Pisma v JETP 26 (1977) 40 (in Russian). 